\title{
Preparation and Validation of User-based Patients Information Leaflets (PILs) for COPD Patients in Indian Regional Languages: A Prospective Observational Study
}

\author{
Ruhul Amin ${ }^{1,4 *}$, Biplab Kumar Dey', Suhaj Abdulsalim²,4, Mohan K. Manu \\ 'Faculty of Pharmaceutical Science, Assam down town University, Panikhaiti, Guwahati, Assam, INDIA. \\ 2Department of Pharmacy Practice, Unaizah College of Pharmacy, Qassim University, SAUDI ARABIA. \\ 'Department of Pulmonary Medicine, Kasturba Medical College Hospital, Manipal University, Manipal, Karnataka, INDIA \\ ${ }^{4}$ Department of Pharmacy Practice, Manipal College of Pharmaceutical Sciences, Manipal University, 576104, Manipal, Karnataka, INDIA.
}

\begin{abstract}
Objectives: Extensive literature survey revealed that chronic obstructive pulmonary disease (COPD) is one of the primary burdens for low-income countries like India. Out of around 30 million COPD patients in India, a considerable number of patients are uneducated about the basics of their disease prevention and medication. Patient information leaflets (PILs) are well accepted materials to educate patients/users about medications, disease and lifestyle modifications. Thus PILs printed in regional languages will certainly act as a valuable tool to disseminate and retain patient's information. Methods: PILs are developed in the English language by referring to various model leaflets that are available from different sources such as "Patient UK", MICROMEDEX Database, GOLD guidelines. The content of the leaflet was validated by physicians. Cloze test was identified as a possible test for assessing the readability of leaflets in English, Kannada, Malayalam and in Hindi. A user-based Cloze test was performed on twenty COPD patients of in each language. Results: The FRE score achieved after the $5^{\text {th }}$ stage of modification was 77.3 , and the FK-GL score
\end{abstract}

achieved was 4.7, which is considered to be good readability of leaflets. User testing scores show significant improvement of knowledge after reading PILs. Conclusion: Present study strongly suggest that the development of patient information leaflet in regional language is likely to have a standard readability score and useful layout design. The prepared leaflet is easily readable and comes out to be user friendly for COPD patients.

Key words: Chronic obstructive pulmonary disease (COPD), PILs, Patient Education.

\section{Correspondence}

Ruhul Amin

Faculty of Pharmaceutical Science, Assam down town University, Panikhaiti, Guwahati, Assam, INDIA.

Email: ruhulglp18@gmail.com

DOI: $10.5530 /$ ijpi.2021.2.43

\section{INTRODUCTION}

Chronic obstructive pulmonary disease (COPD) is a significant burden for a low-income country like India. According to WHO, 65 million people are suffering from COPD. The primary cause of COPD is smoking. ${ }^{1}$ Hence it is most common in the Indian population. Lack of patient education and medication adherence to treatment leads to poor health outcomes in COPD patients. ${ }^{2,3}$ Verbally given information by the doctors cannot be recalled by most patients for a long time. Printed materials will act as a valuable tool for retaining information. ${ }^{4}$ Patient information leaflets (PILs) are universally accepted materials to educate patients/users about medications, disease, and lifestyle modification. ${ }^{5}$ PILs may be considered as a tool for supplementing health education. PILs are the best tools for patients with chronic diseases such as diabetes, hypertension, asthma, COPD, and chronic kidney disease (CKD). ${ }^{6}$ PILs are generally available in the English language. Even though PILs are translated into Indian languages in some cases, their readability cannot be assessed using standard formulae available for English. It is essential to assess the readability and subject PILs to user testing in patients for assessing its acceptability and end user's opinion. Our study aimed to prepare patient information leaflets for COPD and test its readability using user test and significance of PILs for chronic disease.

\section{METHODS}

\section{Study design}

The prospective observational study was conducted over nine months in an inpatient department of pulmonary medicine in a tertiary care teaching hospital. Ethical approval was taken from the institutional human ethics committee (IEC No: IEC404/2015). A total of 80 patients were enrolled in the study after getting consent.

Both male and female patients who diagnosed with COPD, patient willing to participate after given consent were included in the study. The patient who were mentally ill and who had learning difficulty were excluded from the study.

\section{Sample size calculation}

The sample size was calculated based on the change in patient's knowledge of user-testing scores from baseline to post-intervention scores by using the following formula.

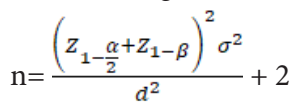

$\sigma=10, Z_{1-\beta}$ is 1.96 (for $\alpha=5 \%$ )

$Z_{1-\beta}$ is 0.84 for power and $d=5$.

This is an open access article distributed under the terms of the Creative Commons Attribution-NonCommercial-ShareAlike 4.0 License, which allows others to remix, tweak, and build upon the work non-commercially, as long as the author is credited and the new creations are licensed under the identical terms. 
$\sigma$ is the mean of the two groups standard deviation

$\mathrm{d}$ is the minimum significant difference between the two groups.

The minimum sample required for this study is 40 .

\section{Preparation of PILs, Validation, and User Testing}

PILs were developed in the English language by referring to various model leaflets that were available from different sources such as "Patient UK," MICROMEDEX Database, GOLD guidelines. ${ }^{7}$ Physicians validated the contents of the leaflet. Changes were made as per physicians' directions, and the leaflet was designed accordingly. Readability of the PIL was checked by www.readability-score.com. After preparing the English leaflets with good readability, they were then translated to Kannada, Malayalam, and Hindi. Translated leaflets were subjected to further validation tests. PILs translation was validated using backtranslation methods. The Baker Able Leaflets Design (BALD) method was used to assess the layout and design characteristics of the PIL (Table $1) .^{8}$

The user test was identified as a possible test for assessing leaflets' readability in English, Kannada, Malayalam, and Hindi. User test was performed in 20 COPD patients for each language (Table 2). User testing was carried out using the questionnaire in COPD patients for all four languages to assess the comprehension of PILs, the patient's knowledge of disease and medications, and feedback was recorded. The statistical analysis was carried using software IBM SPSS Statistics version 22.

\section{RESULTS}

PILs readability score was obtained using www.readability-score.com. ${ }^{9}$ The FRE score achieved after the $5^{\text {th }}$ stage of modification was 77.3 ,

Table 1: Baker Able Leaflet Design (Bald) Assessment Tool.

\begin{tabular}{|c|c|c|c|c|}
\hline $\begin{array}{c}\text { Design } \\
\text { Characteristics }\end{array}$ & 3 Points & 2 Points & 1 Point & 0 Point \\
\hline $\begin{array}{c}\text { Lines } 50-89 \mathrm{~mm} \\
\text { long }\end{array}$ & & & Yes & No \\
\hline $\begin{array}{c}\text { Separation } \\
\text { between lines }\end{array}$ & $>2.8 \mathrm{~mm}$ & $2.2-2.8 \mathrm{~mm}$ & & $<2.2 \mathrm{~mm}$ \\
\hline Lines unjustified & & & Yes & No \\
\hline Serif typeface & & Yes & & No \\
\hline Type size & 12 point & 10-11 point & 9 point & $<9$ point \\
\hline $\begin{array}{l}\text { First Line } \\
\text { indented }\end{array}$ & & & Yes & No \\
\hline Titles lower case & & & Yes & No \\
\hline Italics & & 0 words & $\begin{array}{c}1-3 \\
\text { words }\end{array}$ & $\geq 4$ words \\
\hline Positive advice & & Positive & & Negative \\
\hline $\begin{array}{l}\text { Headings } \\
\text { standout }\end{array}$ & & Yes & & No \\
\hline $\begin{array}{c}\text { Numbers all } \\
\text { Arabic }\end{array}$ & & & Yes & No \\
\hline Boxed text & & & 0-1Box & $>1$ Box \\
\hline Pictures & $\begin{array}{l}\text { Words } \\
\text { count not } \\
\text { replace }\end{array}$ & In between & $\begin{array}{c}\text { In } \\
\text { between }\end{array}$ & $\begin{array}{l}\text { None or } \\
\text { Superfluors }\end{array}$ \\
\hline Number of colors & 4 & 3 & 2 & 1 \\
\hline White space & $>40 \%$ & $30-395$ & $20-29 \%$ & $<20 \%$ \\
\hline Paper quality & $>90 \mathrm{gsm}$ & $75-90 \mathrm{gsm}$ & & $<75 g s m$ \\
\hline
\end{tabular}

and the FK-GL score achieved was 4.7, which is considered to begood readability of leaflets (Figure 1). The BALD assessment score for our PILs was obtained (Figure 2). Overall BALD assessment scores for designed leaflets were high. User testing score was obtained (Figure 3 ) and showed significant improvement of knowledge after reading of PILs.

\section{DISCUSSION}

Communication between patients and healthcare providers is an essential aspect of the patient care process. Proper communication between patient and physician helps in improving the overall outcome of the health care process. PILs are essential communication tools that help patients retain essential information given by the health care provider.

Adepu et al. and Balakrishnan et al. studies revealed that most of the available leaflets have poor readability scores and layout-design. ${ }^{10,11}$ Estrada 2000 et al. conducted a study in the USA and reported that leaflets available in the USA were prepared for high-grade school levels rather than lower school level comprehension. About $88 \%$ of leaflets were written at a $9^{\text {th }}$-grade education level or higher level. ${ }^{12}$

BALD assessment for the designed leaflet was performed for all four languages PILs. A good design and layout leaflet must have a score of 25. The BALD assessment score for our PILs was English=27, Kannada=25, Hindi=26, and Malayalam=25. Overall BALD assessment scores for

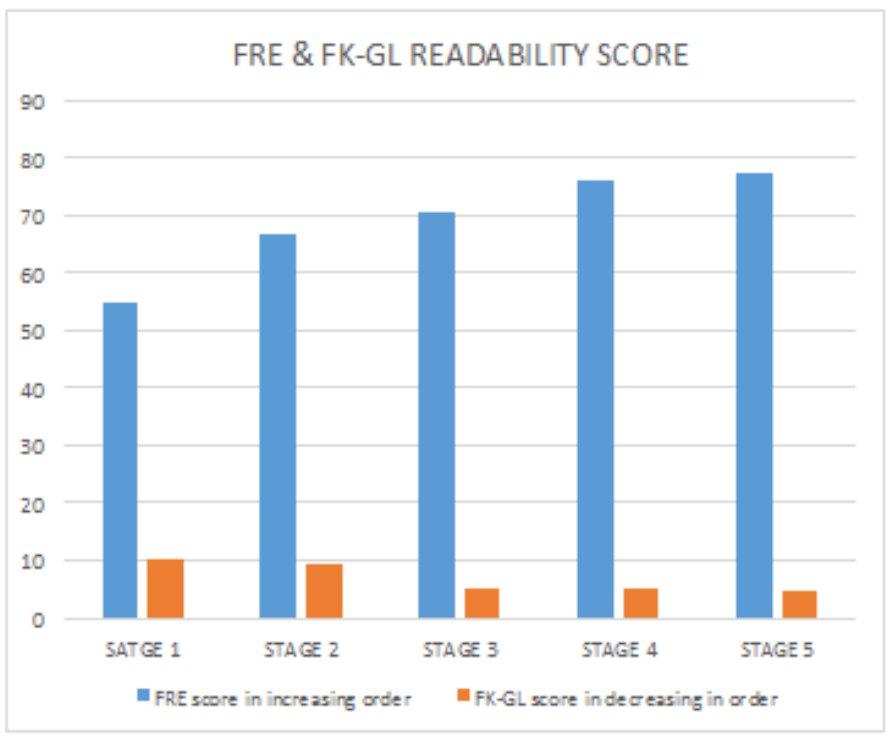

Figure 1: Readability score stage wise after each modification of PILs.

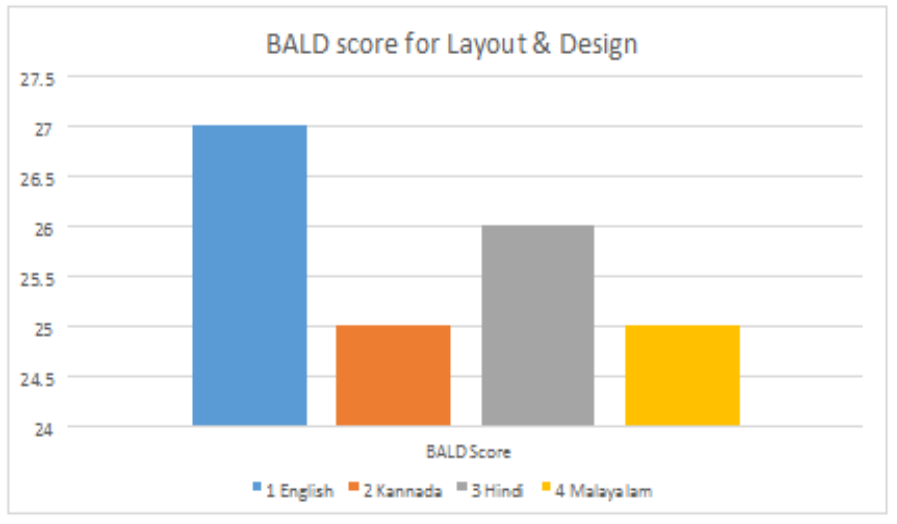

Figure 2: Baker Able Leaflet Design (BALD) assessment score. 
Table 2: Demographics of patients $(P<0.01)$.

\begin{tabular}{|c|c|c|c|c|c|}
\hline Variable & English & Kannada & Malayalam & Hindi & Average \\
\hline Age Mean \pm SD & $60.4 \pm 6.0$ & $72.3 \pm 4.84$ & $62.95 \pm 9.91$ & $60.55 \pm 10.7$ & $64.5 \pm 7.86$ \\
\hline \multicolumn{6}{|l|}{ Gender: } \\
\hline Male & 20 & 18 & 20 & 20 & \\
\hline Female & 0 & 2 & & & \\
\hline \multicolumn{6}{|l|}{ Smoking History } \\
\hline Yes & 20 & 18 & 20 & 20 & \\
\hline No & & 2 & & & \\
\hline \multicolumn{6}{|l|}{$\begin{array}{l}\text { Educational } \\
\text { Qualification }\end{array}$} \\
\hline $10+2$ & $4(20 \%)$ & $13(65 \%)$ & $9(45 \%)$ & $11(55 \%)$ & \\
\hline Degree & $12(60 \%)$ & $5(25 \%)$ & $7(35 \%)$ & $9(45 \%)$ & \\
\hline Master & $4(20 \%)$ & $2(10 \%)$ & $4(20 \%)$ & 0 & \\
\hline FEV1 & $37.35 \pm 12.32$ & $44.5 \pm 12.3$ & $41.1 \pm 9.71$ & $40 \pm 7.47$ & 40.73 \\
\hline GOLD Category & $\begin{array}{c}\text { STAGE } 3 \\
\text { (Severe COPD) }\end{array}$ & $\begin{array}{c}\text { STAGE } 3 \\
\text { (Severe COPD) }\end{array}$ & $\begin{array}{c}\text { STAGE } 3 \\
\text { (Severe COPD) }\end{array}$ & $\begin{array}{c}\text { STAGE } 3 \\
\text { (Severe COPD) }\end{array}$ & \\
\hline
\end{tabular}

${ }^{*} \mathrm{SD}=$ Standard deviation, PUC=Pre university course, FEV1=Forced Expiratory Volume in 1 second, GOLD=Global initiative for chronic obstructive lung disease.

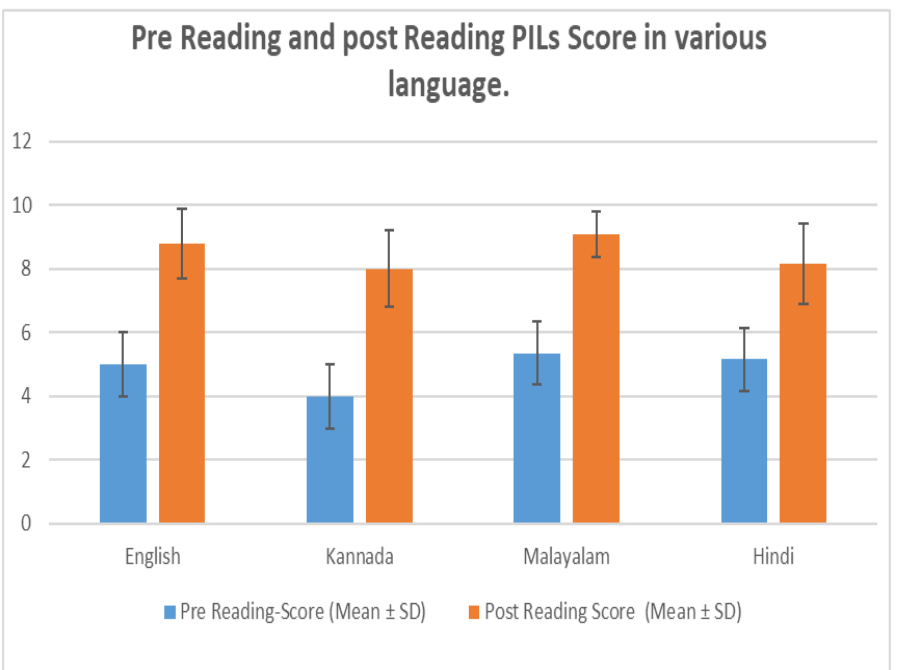

Figure 3: Pre Reading and post Reading PILs Score in various language $(P<0.001, \mathrm{~N}=20$ for Ecah language).

designed leaflets were high. Mathew et al. conducted a study on TB patient's education in India. He prepared a PILs for TB, and the BALD assessment score was English=30, Malayalam $=27$, and Kannada $=28 .{ }^{13}$ His study concluded that a BALD score of 25 or more indicates a good layout and design. Mateti et al. conducted a study in India to test prepared pictogram-based PILs for CKD. He reported that his prepared PILs BALD score was $\geq 25$ (English $=28$ and Kannada 26) and considered a good layout and design. ${ }^{14}$ In our study, all versions of PIL's BALD score was $\geq 25$, which implies that our PILs have an excellent layout and design. User testing was considered as an essential component of PILs evaluation and recommended by many agencies. These user testing studies gave an idea about the comprehension of PILs in local languages and users' preference for the excellent design and layout of PILs.

User testing was carried out using the questionnaire in COPD patients for all four languages to assess the comprehension of PILs and patients' knowledge of disease and medications. The score obtained was (English pre-test $=5 \pm .72$, post-test $=8.8 \pm 1.10(p<0.0001)$, Kannada pre-test $=4$ \pm 1.2 , post-test $=8 \pm 1.2(p<0.0001)$, Malayalam pre-test $=5.35 \pm 1.4$, posttest $=9.1 \pm .71(p<0.0001)$ and Hindi pre-test $=5.15 \pm 1.30$, post-test $=8.15$ \pm 1.26 ( $p<0.0001)$. Redfern et al. conducted a study on PILs for coronary heart disease (CHD) in Australia. He developed PILs for the risk factor of $\mathrm{CHD}$ and concluded that CHD risk factor PILs is an effective approach for secondary prevention of CHD and highly significant $(p<0.05) .^{15}$ Mateti et al. conducted a study in India to test prepared CKD PILs. He observed that, knowledge significantly improved from baseline (posttest $=44.25 \%$ to pre-test $=69.62 \%, p<0.001){ }^{14}$

In 1996, Livingstone et al. conducted a study on community pharmacy services using PILs in a community pharmacy in Brighton, UK. They observed that knowledge significantly improved from $30 \%$ to $65 \%^{16}$ A similar study conducted by Mathew Joy in KMC Manipal (India) reported that patient's experience on TB and drugs significantly improved after reading PILs (Kannada pre-test $=4.1 \pm 1.5$, post-test $=7 \pm 1.1$ and Malayalam pre-test $=4.1 \pm 1.3$ post-tests $=8.1 \pm 1.3, p<0.0001) .{ }^{13}$ This signifies the usefulness of PILs. In our study, the overall improvement of knowledge was observed after reading PILs was statistically significant in all four languages $(p<0.001)$. Our study is demonstrating the applicability of PILs in improving patient's knowledge of COPD. PILs show a positive impact on disease conditions and health outcomes in our study. In India, inadequate health literacy is a barrier to health outcomes, but it can be managed by providing PILs for every medicine and disease conditions. ${ }^{17}$ By using PILs, we can encourage and motivate patients for better medication adherence. User testing tools are considered to be the best tools for PILs preparation in the Indian regional languages. 


\section{Limitations}

- The study population was small, and a larger population may give better results.

- Most of the patients involved in the study included undergraduate and pre-university students, making it difficult to generalize the results.

\section{CONCLUSION}

User testing of PILs in patients showed that the prepared leaflets were readable and acceptable to patients in terms of layout design component and significantly improved patient knowledge on COPD patients. The patients' score for contents assessment showed that the leaflet was kind enough to impart the required knowledge to the patients. This study strongly suggests that the developed patient information leaflet had a significant impact on patient knowledge and user test considered a standard tool for validating multilanguage PILs.

\section{ACKNOWLEDGEMENT}

Authors are grateful to express our gratitude to Manipal College of Pharmaceutical Sciences, Kasturba Hospital, Manipal, and Manipal University, India and Assam down town University, for their support. The authors are thankful to Dr. N. N. Dutta (CMD), Assam down town University for providing a digital resource. We also thank the owner of the domain 'readability-score.com' and the developer of the formula of readability and BALD scoring system for helping our project.

\section{CONFLICT OF INTEREST}

The authors declare that there is no conflict of interest.

\section{ABBREVIATIONS}

BALD: Baker Able Leaflets Design; CKD: Chronic Kidney Disease; COPD: Chronic Obstructive Pulmonary Disease; FRE: The Flesch Reading Ease; FK-GL: The Flesch-Kincaid Grade Level; GOLD: Global Initiative for Chronic Obstructive Lung Disease; PILs: Patient information leaflets; SPSS: Statistical Package for the Social Sciences; WHO: World Health Organisation.

\section{REFERENCES}

1. Quaderi S, Hurst J. The unmet global burden of COPD. Glob Health Epidemiol Genom. 2018;3.

2. Abdulsalim S, Unnikrishnan MK, Manu MK, Alrasheedy AA, Godman B, Morisky $D E$. Structured pharmacist-led intervention programme to improve medication adherence in COPD patients: A randomized controlled study. Res Social Adm Pharm. 2018;14(10):909-14.

3. Koul PA. Chronic obstructive pulmonary disease: Indian guidelines and the road ahead. Lung India. 2013;30(3):175.

4. Prados-Torres A, Cahir C. Interventional Tools to Improve Prescription and Adherence to Medical Plans. Bio Med Res Int. 2015, Article ID 602078.

5. Hargie OD, Morrow NC, Woodman C. Pharmacists' evaluation of key communication skills in practice. Patient Educ Couns. 2000;39(1):61-70.

6. Poornima D, Ramesh A. Assessment of patient information leaflets usefulness in selected chronic diseases: A south Indian based study. Indian J Pharm Practice. 2014;7(1):23.

7. Gold PM. The 2007 GOLD Guidelines: A comprehensive care framework. Respiratory Care. 2009;54(8):1040-9.

8. Baker SJ. Who can read consumer product information?. Aust J Hospital Pharm. 1997;27(2):126-31.

9. www.readability-score.com [Available from: http://www.readability-score.com.

10. Adepu R, Nagavi B, Kumar BM. Patient counseling; practicing community pharmacists' perceptions from two South Indian states. Indian J Pharm Sci. 2004;66(1):44.

11. Balkrishnan R. The importance of medication adherence in improving chronic disease related outcomes: What we know and what we need to further know. Med Care. 2005;43(6):517-20.

12. Estrada CA, Hryniewicz MM, Higgs VB, Collins C, Byrd JC. Anticoagulant patient information material is written at high readability levels. Stroke. 2000;31(12):2966-70

13. Surulivelrajan M, Joy M, Suhaj A, Rajesh V, Manu MK. Study to assess the utility of cloze test in readability assessment of patient information leaflets in English and Indian languages. Asian J Pharm Health Sci. 2013;3(4):824-9.

14. Mateti UV, Nagappa AN, Attur RP, Bairy M, Nagaraju SP, Mallayasamy S, et al. Preparation, validation and user-testing of pictogram-based patient information leaflets for hemodialysis patients. Saudi Pharm J. 2015;23(6):621-5.

15. Redfern J, Ellis E, Briffa T, Freedman SB. Development and testing of innovative patient resources for the management of coronary heart disease (CHD): A descriptive study. BMC Health Services Res. 2006;6(1):95.

16. Livingstone CR, Pugh AL, Winn S, Williamson VK. Developing community pharmacy services wanted by local people: Information and advice about prescription medicines. Int J Pharm Practice. 1996;4(2):94-102.

17. Dickinson D, Raynor DK, Duman M. Patient information leaflets for medicines: using consumer testing to determine the most effective design. Patien Patient Educ Couns. 2001;43(2):147-59

Article History: Submission Date : 11-02-2021; Revised Date : 23-03-2021; Acceptance Date : 02-04-2021.

Cite this article: Amin R, Dey BK, Abdulsalim S, Manu MK. Preparation and Validation of User-based Patients Information Leaflets (PILs) for COPD Patients in a Regional Language- A Prospective Observational Study. Int. J. Pharm. Investigation, 2021;11 (2):244-7. 